Copyright (C) 2016 by Academic Publishing House Researcher

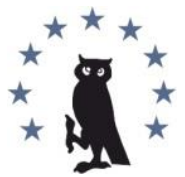

Published in the Russian Federation

Biogeosystem Technique

Has been issued since 2014 .

ISSN: 2409-3386

E-ISSN: $2413-7316$

Vol. 7, Is. 1, pp. 41-48, 2016

DOI: 10.13187/bgt.2016.7.41

www.ejournal19.com

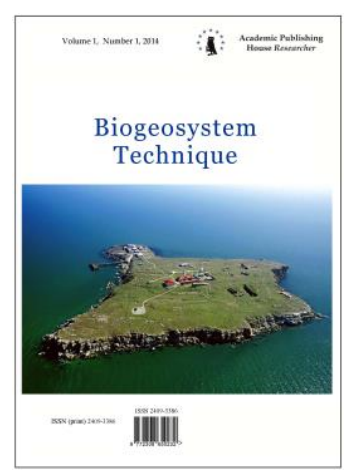

UDC 631.95:628.516:615.849

\title{
Organization of Crop Production at Radioactively Contaminated Areas: Environmental and Biological Aspects
}

\author{
${ }^{1}$ Aleksandr I. Dutov \\ ${ }^{2}$ Fedor N. Lisetskii \\ ${ }^{3}$ Sergey V. Dubchak
}

\begin{abstract}
${ }^{1}$ Belgorod State Agricultural University named after V. Gorin, Russian Federation 308503 Belgorod region, Belgorod district, p. Maisky, Vavilova, 1

${ }^{2}$ Belgorod State National Research University, Russian Federation

308015 Belgorod, st. 308015, str. Pobedy, 85

${ }_{3}^{3}$ State Ecological Academy of Postgraduate Education and Management, Ukraine

3035, Kiev, str. Lipkovsky, 35

${ }^{1}$ Dr. (Agriculture), Professor

E-mail:dutov_bsau@mail.ru

${ }_{2}^{2} \operatorname{Dr}$ (Geography), Professor

E-mail: liset@bsu.edu.ru

$3 \mathrm{PhD}$ (Agriculture)

E-mail: sergiy.dubchak@yahoo.com
\end{abstract}

\section{Abstract}

The modern environmental and biological approaches to the selection of field agricultural crops for cultivation at contaminated areas are considered. It is established, that the satiation of rotations with agricultural crops differed by potentially low capacity to accumulate ${ }^{137} \mathrm{Cs}$, can significantly extend the areal of radioactively contaminated lands use for production of guaranteed safe products. The influence of arbuscular mycorrhizal fungi on radiocaesium uptake by plants is analyzed. The ability of arbuscular mycorrhiza to modify significantly radiocaesium accumulation by agricultural crops is found.

Keywords: greening of agriculture, radiocaesium, agricultural crops, radioactively contaminated areas, arbuscular mycorrhizal fungi, mycorrhizal colonization.

\section{Введение}

Поздняя фаза развития радиационной ситуации характеризуется тем, что одним из наиболее значимых радионуклидов, который определяет степень радиационной опасности

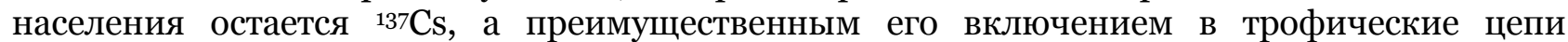
является корневое поступление из почвы в растения. Указанная закономерность подтверждена как опытом преодоления последствий аварии на Чернобыльской АЭС (1986 г.) [1, 2, 3] , так и на АЭС «Фукусима» (2011 г.) [4]. Поэтому особенностью растениеводства в этих условиях является внедрение комплекса противорадиационных мероприятий, направленных на минимизацию дозы облучения населения путем 
производства гарантированно радиоэкологически безопасной сельскохозяйственной продукции $[5,6,7]$.

В последнее время значительное внимание уделяется экологизации земледелия, в частности инвайронментальним биотехнологиям, которые предусматривают комбинированное использование биологических особенностей растений и их взаимоотношений с определенными видами почвенных микроорганизмов [8]. Среди таких микроорганизмов особое значение имеют арбускулярные микоризные (АМ) грибы, поскольку около $90 \%$ растений формируют с ними симбиотические связи, образуя микоризные ассоциации [9]. Наряду с сохранением и повышением плодородия почвы, применение AM грибов значительно уменьшает химическую нагрузку на окружающую среду (из-за снижения потребности в применении средств химизации, в частности минеральных удобрений), что особенно актуально на территориях, загрязненных радионуклидами после ядерных и радиационных инцидентов.

\section{Материалы и методы исследований}

Удельную активность радиоактивного цезия в подземных и надземных частях исследуемых растений определяли на полупроводниковом гамма-спектрометре с $\mathrm{HP}-\mathrm{Ge}$ детектором (относительная эффективность 15\%, разрешение 2,5 кэВ для энергии 1,33 МэВ).

Растения в лабораторных опытах выращивали на почве с искусственно внесенным и гомогенно распределенным ${ }^{134} \mathrm{Cs}$, удельная активность которого была 77000 Бк/кг.

Отбор почвенных образцов и их подготовку к анализу осуществляли по общепринятым методикам с учетом специфики научно-исследовательских работ в области сельскохозяйственной радиологии [10].

Для оценки накопления радионуклидов в урожае при различной плотности загрязнения почвы использовали коэффициент перехода (КП) радиоцезия из почвы в растения - содержание радионуклида в растении при плотности загрязнения почвы, равной

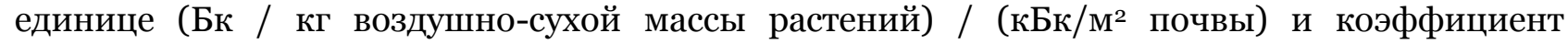
накопления (КН) - отношение удельной активности радионуклида в воздушно-сухой массе растений к удельной активности радионуклида в почве (Бк / кг воздушно-сухой массы растений) / (Бк / кг почвы).

Изучение влияния арбускулярных микоризных (AM) грибов на накопление радиоцезия сельскохозяйственными культурами в лабораторных условиях проводили на растениях люцерны (Medicago truncatula) и подсолнечника (Helianthus annuus). В качестве иннокулянта использован AM гриб Glomus intraradices (штамм BIO; компания BIORIZE, м. Дижон, Франция), который является широко распространенным в различных типах почв и проявляет высокую колонизационную способность в симбиозе со многими видами растений $[11,12]$.

Колонизацию АМ грибами определяли с помощью светового микроскопа Nikon Eclipse 800 (Япония) с системой фоторегистрации Nikon FDX-35. Корни растений окрашивали раствором 0,01\% голубого анилина и 80\% молочной кислоты. Количественный анализ микоризной колонизации растений внутрикорневыми структурами АМ грибов проводили по методу Трувелота [13] с использованием шестиуровневой шкалы колонизации.

Измерения концентрации стабильных металлов (K, Ca, Ti, Cr, Mn, Fe, Ni, Cu, Zn, As, Se, $\mathrm{Rb}, \mathrm{Sr}, \mathrm{Cs}, \mathrm{Y}$ и $\mathrm{Pb}$ ) в надземных и подземных частях растений и почве проводили с использованием метода флуоресцентного анализа с полным рентгеновским отражением (TXRF-анализ).

\section{Результаты и обсуждение}

Инвайронментально-биологические подходы к подбору сельскохозяйственных культур при составлении севооборотов для загрязненных радионуклидами территорий базируются на потенциальной способности растений к накоплению радионуклидов. Обобщение многолетних экспериментальных данных позволило разделить по этому признаку наиболее распространенные полевые сельскохозяйственные культуры на три условных группы (рис.

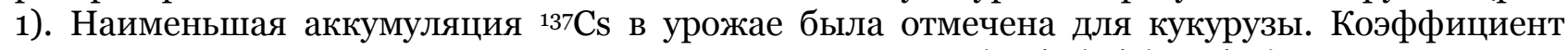
перехода радионуклида в зерно культуры составил о,о7 (Бк/кг) / (кБк/м²). Потенциальная способность к аккумуляции радиоактивного цезия в зерне озимой и яровой пшеницы, 
ячменя и тритикале также была относительно невысока, но в 1,5-2,3 раза выше, чем у кукурузы. К группе культур с потенциально невысокой способностью к накоплению ${ }^{137 \mathrm{Cs}}$ относят и картофель [14]. Коэффициент перехода радионуклида в клубни этой культуры занимает промежуточное положение между озимой пшеницей и ячменем.

Более высоким потенциальным накоплением радионуклида отличалась группа крупяных культур. Если содержание радиоцезия в просе было на уровне озимой ржи, то в

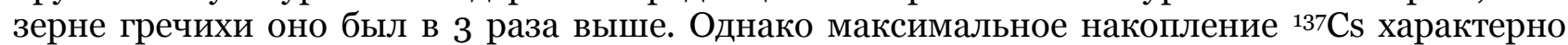
для группы зерновых бобовых культур. В частности, в зерне гороха этот показатель был в 13 раз выше по сравнению с кукурузой.

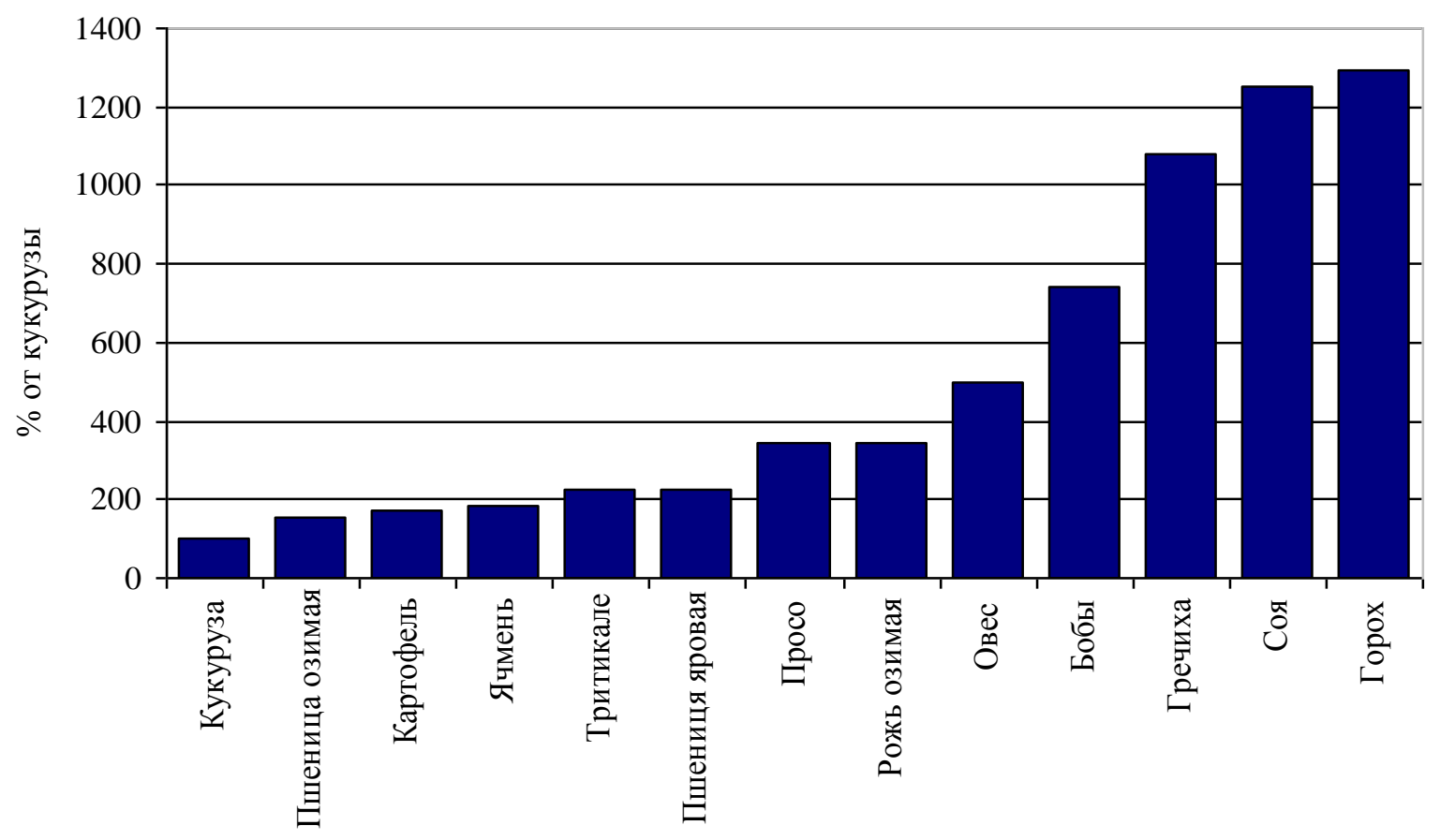

Puc. 1. Относительное накопление ${ }^{137}$ Сs полевыми сельскохозяйственными культурами, \% от кукурузы

Учитывая изложенное, следует отметить, что путем введения в севообороты тех сельскохозяйственных культур, отличающихся потенциально невысокой способностью к накоплению радиоцезия, можно значительно расширить ареал использования радиоактивно загрязненных земель для производства продукции, которая будет гарантированно соответствовать действующим гигиеническим нормативам, снять радиационно-экологическую критичность аграрных экосистем.

Полученные результаты также свидетельствуют о способности арбускулярной микоризы существенно модифицировать накопление радиоцезия растениями. В частности, инокуляция АМ грибом $G$. intraradices обусловила уменьшение коэффициента накопления ${ }^{134} \mathrm{Cs}$ в надземных органах люцерны по сравнению с немикоризованым контролем на 52 \%. В то же время микоризованные растения люцерны аккумулировали в корнях на 19 \% больше

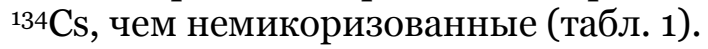




\section{Таблица 1}

\section{Влияние арбускулярной микоризации на накопление $134 \mathrm{Cs}$ в люцерне (Medicago truncatula) и подсолнечнике (Helianthus annuus)*}

\begin{tabular}{|c|c|c|c|c|c|c|c|}
\hline \multirow{2}{*}{ 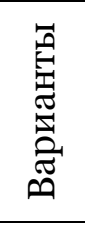 } & \multicolumn{2}{|c|}{$\begin{array}{c}\text { Удельная } \\
\text { активность, Бк·кг-1 }\end{array}$} & \multicolumn{2}{|c|}{$\begin{array}{l}\text { Активность } \\
\text { растения, } \\
\text { Бк/растение } \\
\end{array}$} & \multicolumn{2}{|c|}{$\begin{array}{c}\text { Коэффициєнт } \\
\text { накопления (КН) }\end{array}$} & \multirow{2}{*}{$\begin{array}{c}\text { Соотношение } \\
\text { активности, подз./надз. } \\
\text { частей растений }\end{array}$} \\
\hline & $\begin{array}{l}\text { подз. } \\
\text { часть }\end{array}$ & $\begin{array}{l}\text { надз. } \\
\text { часть }\end{array}$ & $\begin{array}{l}\text { подз. } \\
\text { часть }\end{array}$ & $\begin{array}{l}\text { надз. } \\
\text { часть }\end{array}$ & $\begin{array}{l}\text { подз. } \\
\text { часть }\end{array}$ & $\begin{array}{l}\text { надз. } \\
\text { часть }\end{array}$ & \\
\hline \multicolumn{8}{|c|}{ Medicago truncatula } \\
\hline HM & $\begin{array}{c}106400 \pm \\
19986^{\mathrm{a}}\end{array}$ & $\begin{array}{c}132100 \pm \\
15505^{\mathrm{b}}\end{array}$ & $\begin{array}{c}2.3 \pm \\
0.2^{\mathrm{a}}\end{array}$ & $\begin{array}{c}12.3^{ \pm} \\
0.6^{\mathrm{b}}\end{array}$ & $\begin{array}{c}1.38 \pm \\
0.21^{\mathrm{a}}\end{array}$ & $\begin{array}{l}1.72 \pm \\
0.20^{b}\end{array}$ & $0.81 \pm 0.28^{a}$ \\
\hline M & $\begin{array}{c}126441 \pm \\
11463^{\mathrm{b}} \\
\end{array}$ & $\begin{array}{c}86888 \pm \\
20022^{\mathrm{a}} \\
\end{array}$ & $\begin{array}{c}3.1 \pm \\
0.1^{\mathrm{b}}\end{array}$ & $\begin{array}{l}9.3^{ \pm} \\
0.6^{\mathrm{a}} \\
\end{array}$ & $\begin{array}{c}1.64 \pm \\
0.15^{\mathrm{b}}\end{array}$ & $\begin{array}{l}1.13^{ \pm} \\
0.26^{\mathrm{a}} \\
\end{array}$ & $1.45 \pm 0.41^{\mathrm{b}}$ \\
\hline \multicolumn{8}{|c|}{ Helianthus annuus } \\
\hline $\mathrm{HM}$ & $\begin{array}{c}38412 \pm \\
3933^{\mathrm{a}}\end{array}$ & $\begin{array}{c}26202 \pm \\
1147^{\mathrm{a}}\end{array}$ & $\begin{array}{c}0.4^{ \pm} \\
0.1^{\mathrm{a}}\end{array}$ & $\begin{array}{c}6.4 \\
\pm 1.8^{\mathrm{a}} \\
\end{array}$ & $\begin{array}{l}0,50 \pm \\
0.05^{\mathrm{a}}\end{array}$ & $\begin{array}{c}0,34 \pm \\
0.04^{\mathrm{a}}\end{array}$ & $1.47 \pm 0.21^{\mathrm{a}}$ \\
\hline M & $\begin{array}{c}378932 \pm \\
10233^{\mathrm{b}} \\
\end{array}$ & $\begin{array}{c}245353 \pm \\
4502^{\mathrm{b}} \\
\end{array}$ & $\begin{array}{c}6.5^{ \pm} \\
1.2^{\mathrm{b}} \\
\end{array}$ & $\begin{array}{c}104.1 \pm \\
4.6^{\mathrm{b}}\end{array}$ & $\begin{array}{l}4,92 \pm \\
0.08^{b}\end{array}$ & $\begin{array}{l}3,19 \pm \\
0.06^{b}\end{array}$ & $1.54 \pm 0.10^{\mathrm{a}}$ \\
\hline
\end{tabular}

* различные буквы над величинами в таблице означают статистически существенные различия между микоризованными (М) и немикоризованными (HM) растениями $(\mathrm{P}<0,05)$.

Таким образом, под действием арбускулярного микоризного симбиоза произошло увеличение на 80\% соотношения между удельной активностью ${ }^{134} \mathrm{Cs}$ в подземных и надземных частях растений люцерны и, следовательно, - уменьшение переноса радионуклида из корневой системы в надземные органы растения.

Противоположный эффект влияния арбускулярной микоризы наблюдался у подсолнечника обычного (Helianthus annuus). В надземной и подземной частях растений, инокулированных AM грибом был отмечен почти десятикратный рост коэффициентов накопления ${ }^{134 \mathrm{Cs}}$ (c 0,50 до 4,92 в корневой системе и 0,34 до 3,19 в надземных органах) по сравнению с контрольным вариантом без проведения иннокуляции. Микоризованные

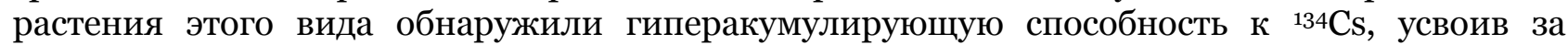
трехмесячный период культивации относительно высокую (0,22 - 0,27\%) часть ${ }^{134} \mathrm{Cs}$ из почвы.

Следует отметить, что механизм ограничения или интенсификации поступления в растения радиоактивного цезия АМ грибами детально не изучен. На сегодня известно два основных процесса: первый - это образование АМ грибом соединений, которые переводят поллютанты в почве в необменную форму, иногда с его фиксацией на внешней поверхности мицелия. И второй - компартментализация - перемещение поглощенного поллютанта к наиболее устойчивым к его воздействию органам АМ гриба или к внутриклеточному пространству с последующей изоляцией от цитоплазмы и депонированием [11].

Микоризованные растения люцерны и подсолнечника, выращиваемые на почве, загрязненной ${ }^{134} \mathrm{Cs}$, и в «контрольном» варианте характеризовались значительными уровнями АМ колонизации (84-98\%). Колонизация фрагментов корней растений была однородной, а внутрикорневые структуры АМ гриба G. intraradices образовывали Arum-тип микоризы (рис. 2). 

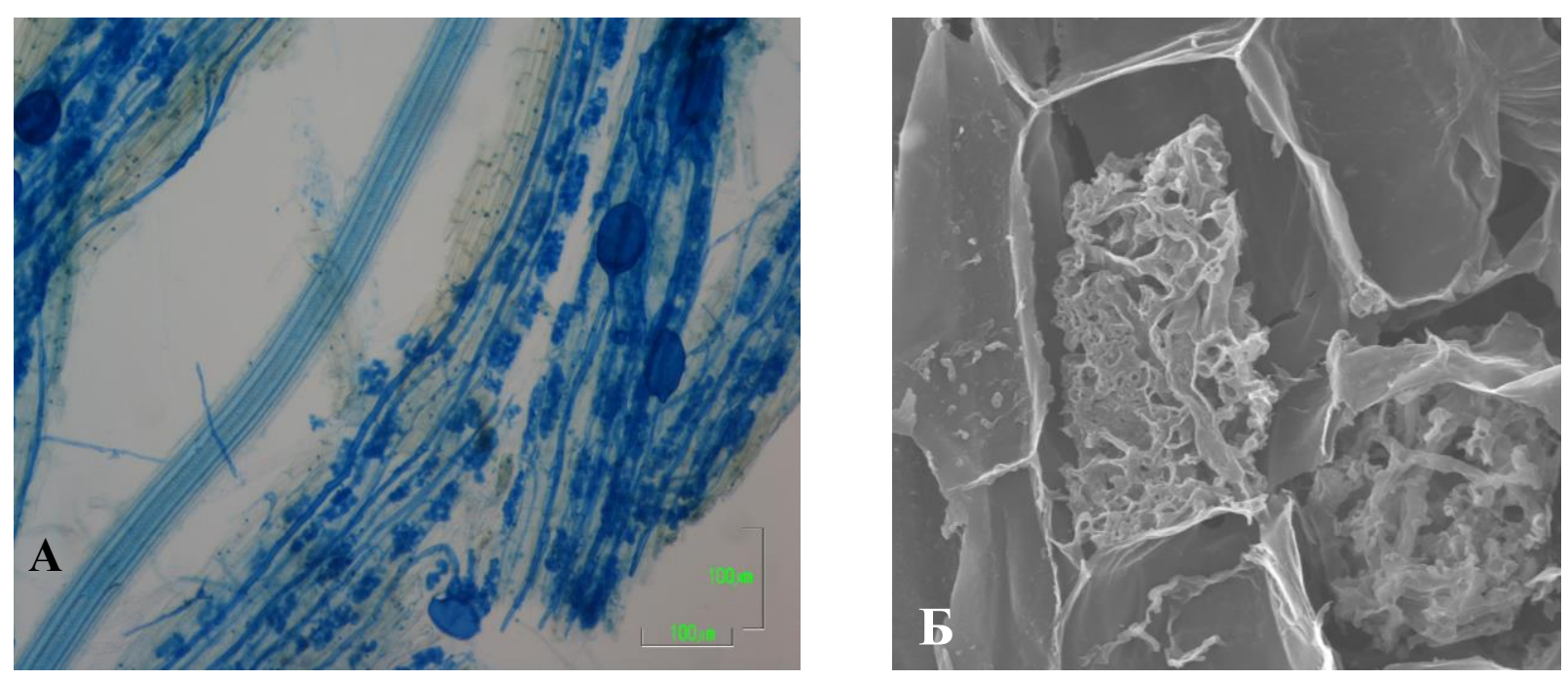

Puc. 2. Арбускулы и везикулы АМ гриба G. intraradices:

A - фото светового микроскопа в корнях люцерны; Б - арбускулы в клетках кортикального слоя корней подсолнечника (фото с электронного микроскопа, ×2000)

Высокое содержание арбускул в колонизированных корнях всех видов растений (52-89 \%) свидетельствует об эффективном функционировании и хорошем качественном состоянии микоризы. По данным, приведенным на рис. 3, видно, что параметры AM колонизации корней люцерны были значительно выше, чем у подсолнечника.

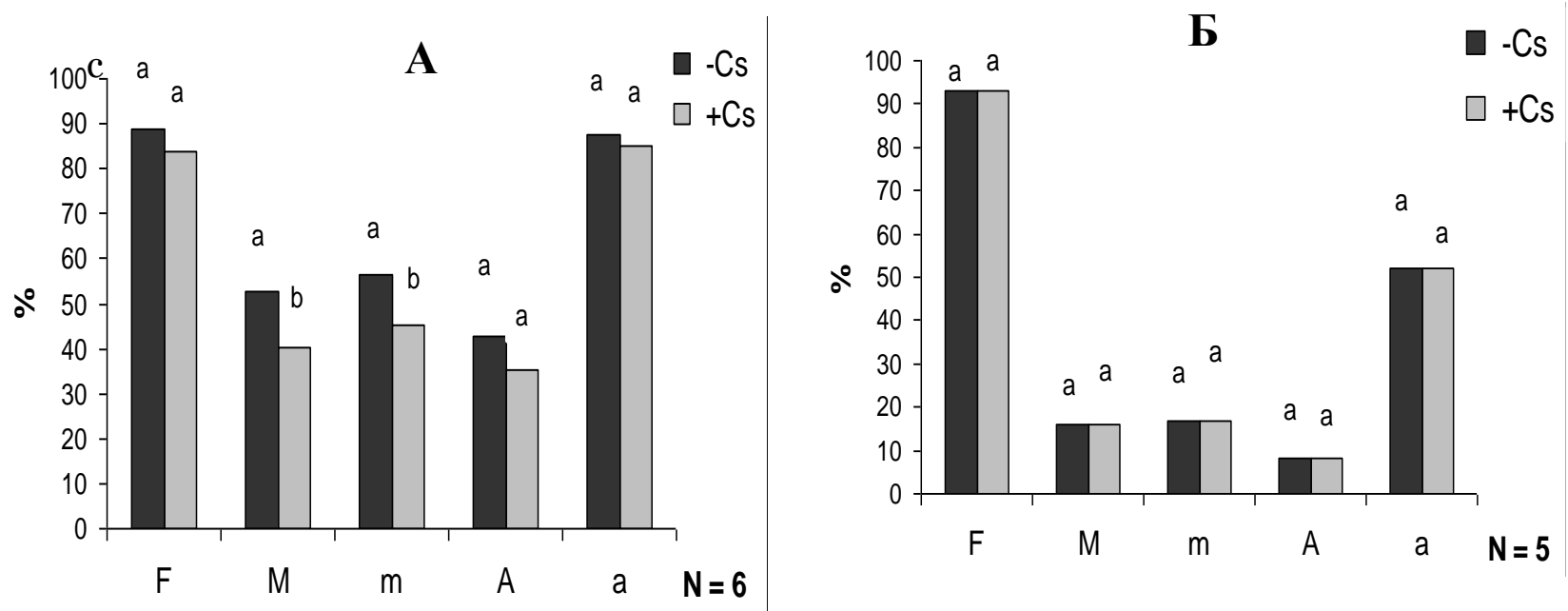

Puc. 3. Параметры арбускулярной микоризной колонизации корневой системы растений люцерны (А) и подсолнечника (Б) грибом G. intraradices, выращенных на почве, загрязненной ${ }^{134} \mathrm{Cs}$ («+ Cs») и без радиоцезия («- Cs»), \%

$\mathrm{F}$ - Общая степень колонизации; M, m - интенсивность микоризной колонизации (общая и в микоризированных фрагментах корней, соответственно); А, а - содержание арбускул (общий и в микоризированных фрагментах корней с арбускулами, соответственно)

При этом следует отметить, что присутствие радиоактивного цезия в почве существенно не повлияло на параметры АМ колонизации подсолнечника и одновременно привело к уменьшению (на 10-12 \%) показателей интенсивности микоризной колонизации (М и m) в отношении люцерны. 


\section{Заключение}

Как показано ранее по результатам радиационно-экологической оценки перспектив сельскохозяйственного использования Чернобыльской зоны отселения [15], наиболее рациональным направлением развития сельскохозяйственной деятельности в этих условиях является мясное животноводство и производство сельскохозяйственного сырья для последующей глубокой переработки.

Инвайронментально-биологические аспекты организации растениеводства на радиоактивно загрязненных территориях предусматривают более полное использование потенциальной способности сельскохозяйственных растений накапливать радионуклиды с помощью определенных видов почвенных микроорганизмов, что значительно уменьшает химическую нагрузку на агроэкосистемы, способствует сохранению и воспроизводству плодородия загрязненных почв, скорейшей их реабилитации.

AM грибы могут способствовать трансформации и иммобилизации в своих структурах радиоактивного цезия и ограничивать его доступность отдельным видам растений. Эффективность микоризы в процессах переноса радиоцезия не определяется интенсивностью АМ колонизации и демонстрирует зависимость коэффициентов накопления радионуклида от биологических особенностей растений. В то же время более эффективное использование АМ грибов в системе противорадиационных мероприятий на загрязненной радионуклидами территории требует более полного изучения

\section{Примечания}

1. Абагян А.А. Информация об аварии на Чернобыльской АЭС и ее последствиях, подготовленная для МАГАТЭ // Атомная энергия. 1986. Т. 61. Вып. 5. С. 301-320.

2. Національна доповідь України «25 років Чорнобильської катастрофи. Безпека майбутнього». Київ: КІМ, 2011. 395 с.

3. Дутов А.И., Булыгин С.Ю. Инновационные подходы к рациональному сельскохозяйственному использованию загрязненных земель в поздний период развития радиационной ситуации после аварии на ЧАЭС // Инновации в АПК: проблемы и перспективы. 2014. № 4. С. 66-74.

4. Hirose K. Fukushima Dai-ichi nuclear power plant accident: summary of regional radioactive deposition monitoring results // Journal of environmental radioactivity. 2012. Vol. 111. P. 13-17.

5. Ведення сільськогосподарського виробництва на територіях, забруднених внаслідок Чорнобильської катастрофи у віддалений період (методичні рекомендації) / редкол.: Б.С. Пристер (голова) та ін. Київ : Атіка-Н, 2007. 195 с.

6. Пристер Б.С. Проблемы сельскохозяйственной радиоэкологии и радиобиологии при загрязнении окружающей среды молодыми смесями продуктов ядерного деления. Чернобыль. Київ : Книга, 2008. 320 с.

7. Дутов О.I. Сучасні підходи до раціонального використання радіоактивно забруднених земель (на прикладі аварії на Чорнобильській AEC) // Агрохімія i грунтознавство. 2012. Вып. 77. С. 38-43.

8. Entry J.A., Astrud L.S., and Reeves M. Accumulation of ${ }^{137 \mathrm{Cs}}$ and ${ }^{90} \mathrm{Sr}$ from contaminated soil by three grass species inoculated with mycorrhizal fungi // Environ. Pollut. 1999. Vol. 104. P. 449-457.

9. $\quad$ Smith S.E., and Read D.J. Mycorrhizal Symbiosis. Academic Press, San Diego. 1997. $312 \mathrm{p}$.

10. Методичний посібник з організації проведення науково-дослідних робіт в галузі сільськогосподарської радіології. Київ, 1992. 136 с.

11. Кріпка Г.В., Сорочинський Б.В. Отримання та випробування інокулятів арбускулярних мікоризних грибів 3 метою модифікації поглинання радіонуклідів рослинами // Зб. наукових праць Інституту ядерних досліджень. 2003. №2 (10). С. 80-84.

12. Meharg A.A. The mechanistic basis of interactions between mycorrhizal associations and toxic metal cations // Mycol. Res. 2003. Vol. 107. P. 1253-1265.

13. Trouvelot A., Kough J.L., and Gianinazzi-Pearson V. Mesure du taux de mycorhization VA d'un système radiculaire. Recherche de méthodes d'estimation ayant une signification 
fonctionnelle // Physiological and Genetical Aspects of Mycorrhizae. / Gianinazzi-Pearson, V., Gianinazzi, S. (Eds.). INRA Press. Paris. P. 217-221.

14. Дутов O.I. Сільськогосподарські культури для сівозмін в умовах радіоактивного забруднення грунту // Збірник наукових праць ХДАУ. Серія рослинництво, селекція і насінництво, овочівництво. 1999. № 4. С. 164-168.

15. Дутов А.И., Булыгин С.Ю., Лисецкий Ф.Н. Чернобыльская зона отселения: радиационно-экологические аспекты перспектив сельскохозяйственного использования территории // Научные ведомости Белгородского государственного университета. Серия: Естественные науки. 2015. Т. 31. № 9 (206). С. 186-191.

\section{References}

1. Abagjan A.A. Informacija ob avarii na Chernobyl'skoj AJeS i ee posledstvijah, podgotovlennaja dlja MAGATJe // Atomnaja jenergija. 1986. T. 61. № 5. P. 301-320.

2. Nacional'na dopovid' Ukraïni «25 rokiv Chornobil's'koï katastrofi. Bezpeka majbutn'ogo». Kiïv: KIM, 2011. 395 p.

3. Dutov A.I., Bulygin S.Ju. Innovacionnye podhody $\mathrm{k}$ racional'nomu sel'skohozjajstvennomu ispol'zovaniju zagrjaznennyh zemel' v pozdnij period razvitija radiacionnoj situacii posle avarii na ChAJeS // Innovacii v APK: problemy i perspektivy. 2014. № 4. P. 66-74.

4. Hirose K. Fukushima Dai-ichi nuclear power plant accident: summary of regional radioactive deposition monitoring results // Journal of environmental radioactivity. 2012. Vol. 111. P. 13-17.

5. Vedennja sil's'kogospodars'kogo virobnictva na teritorijah, zabrudnenih vnaslidok Chornobil's'koï katastrofi u viddalenij period (metodichni rekomendaciï) / redkol.: B.S. Prister (golova) ta in. Kïv : Atika-N, 2007. 195 p.

6. Prister B.S. Problemy sel'skohozjajstvennoj radiojekologii i radiobiologii pri zagrjaznenii okruzhajushhej sredy molodymi smesjami produktov jadernogo delenija. Chernobyl'. Kiïv : Kniga, 2008. 320 p.

7. Dutov O.I. Suchasni pidhodi do racional'nogo vikoristannja radioaktivno zabrudnenih zemel' (na prikladi avarii na Chornobil's'kij AES) // Agrohimija i gruntoznavstvo. 2012. № 77. P. 38-43.

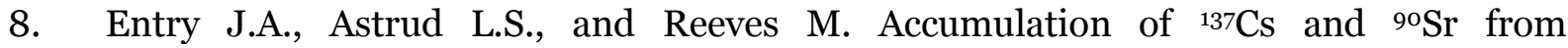
contaminated soil by three grass species inoculated with mycorrhizal fungi // Environ. Pollut. 1999. Vol. 104. P. 449-457.

9. $\quad$ Smith S.E., and Read D.J. Mycorrhizal Symbiosis. Academic Press, San Diego. 1997. $312 \mathrm{p}$.

10. Metodichnij posibnik $\mathrm{z}$ organizaciï provedennja naukovo-doslidnih robit $\mathrm{v}$ galuzi sil's'kogospodars'koï radiologiï. Kiïv, 1992. 136 p.

11. Kripka G.V., Sorochins'kij B.V. Otrimannja ta viprobuvannja inokuljativ arbuskuljarnih mikoriznih gribiv z metoju modifikaciï poglinannja radionuklidiv roslinami // Zb. naukovih prac' Institutu jadernih doslidzhen'. 2003. №2 (10). P. 80-84.

12. Meharg A.A. The mechanistic basis of interactions between mycorrhizal associations and toxic metal cations // Mycol. Res. 2003. Vol. 107. P. 1253-1265.

13. Trouvelot A., Kough J.L., and Gianinazzi-Pearson V. Mesure du taux de mycorhization VA d'un système radiculaire. Recherche de méthodes d'estimation ayant une signification fonctionnelle // Physiological and Genetical Aspects of Mycorrhizae. / Gianinazzi-Pearson, V., Gianinazzi, S. (Eds.). INRA Press. Paris. P. 217-221.

14. Dutov O.I. Sil's'kogospodars'ki kul'turi dlja sivozmin v umovah radioaktivnogo zabrudnennja gruntu // Zbirnik naukovih prac' HDAU. Serija roslinnictvo, selekcija i nasinnictvo, ovochivnictvo. 1999. № 4. P. 164-168.

15. Dutov A.I., Bulygin S.Ju., Liseckij F.N. Chernobyl'skaja zona otselenija: radiacionnojekologicheskie aspekty perspektiv sel'skohozjajstvennogo ispol'zovanija territorii // Nauchnye vedomosti Belgorodskogo gosudarstvennogo universiteta. Serija: Estestvennye nauki. 2015. T. 31. № 9 (206). P. 186-191. 
УДК 631.95:628.516:615.849

\title{
Организация растениеводства на радиоактивно загрязненных территориях: инвайронментально-биологические аспекты
}

\author{
1 Александр Иванович Дутов \\ 2 Федор Николаевич Лисецкий \\ 3 Сергей Валерьевич Дубчак
}

1 Белгородский государственный аграрный университет им. В.Я. Горина, Российская Федерация 308503 Белгородская обл., Белгородский р-н, п. Майский, ул. Вавилова, 1

${ }^{2}$ Белгородский государственный национальный научно-исследовательский университет, Российская Федерация 308015 Белгород, ул. Победы, 85

3 Государственная экологическая академия последипломного образования и управления, Украина

3035 г. Киев, ул. Липковского, 35

${ }^{1}$ Доктор сельскохозяйственных наук, профессор

E-mail: dutov_bsau@mail.ru

${ }^{2}$ доктор географических наук, профессор

E-mail: liset@bsu.edu.ru

${ }^{2}$ Кандидат сельскохозяйственных наук

E-mail: sergiy.dubchak@yahoo.com

Аннотация. Рассмотрены современные инвайронментально-биологические подходы к подбору полевых сельскохозяйственных культур для выращивания на радиоактивно загрязненных территориях. Установлено, что насыщением севооборотов сельскохозяйственными культурами, которые отличаются потенциально невысокой

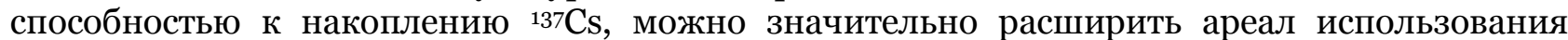
радиоактивно загрязненных земель для производства гарантированно безопасной продукции. Проанализировано влияние арбускулярних микоризных грибов на поступление радиоцезия к растениям. Установлена способность арбускулярной микоризы существенно модифицировать накопления радиоцезия сельскохозяйственными культурами.

Ключевые слова: экологизация земледелия, радиоцезий, сельскохозяйственные культуры, радиоактивно загрязненные территории, арбускулярные микоризные грибы, микоризная колонизация. 